WSRC-TR-92-549

\title{
HEME AND HEPA FILTER ELEMENT DISSOLUTION PROCESS (U)
}

by C. A. Cicero

WSRC-TR- -92-549

Westinghouse Savannah River Company

Savannah River Site

DE93 011705

Aiken, South Carolina 29808

Other Authors:

This paper was prepared in connection with work done under Contract No. DE-AC09-89SR18035 with the U. S. Department of Energy. By acceptance of this paper, the publisher and/or recipient acknowledges the U. S. Government's right to retain a nonexclusive, royalty-free license in and to any copyright covering this paper, along with the right to reproduce and to authorize others to reproduce all or part of the copyrighted paper.

\section{MASTER}




\section{DISCLAIMER}

This report was prepared as an account of work sponsored by an agency of the United States Government. Neither the United States Government nor any agency thereof, nor any of their employees, makes any warranty, express or implied, or assumes any legal liability or responsibility for the accuracy, completeness, or usefulness of any information, apparatus, product, or process disclosed, or represents that its use would not infringe privately owned rights. Reference herein to any specific commercial product, process, or service by trade name, trademark, manufacturer, or otherwise does not necessarily constitute or imply its endorsement, recommendation, or favoring by the United States Government or any agency thereof. The views and opinions of authors expressed herein do not necessarily state or reflect those of the United States Government or any agency thereof.

This report has been reproduced directly from the best available copy.

Available to DOE and DOE contractors from the Office of Scientific and Technical Information, P.O. Box 62, Oak Ridge, TN 37831; prices available from (615) 576-8401, FTS 626-8401.

Available to the public from the National Technical Information Service, U.S. Department of Commerce, 5285 Port Royal Rd., Springfield, VA 22161. 
November 23, 1992 WSRC-TR-92-549

TO: $\quad$ M.J. Plodinec

FROM: $\quad$ C.A. Cicero

BHMT AND BEPA FIITER GIJMFNT DISSOTUTION PROCESS (UI)

\section{SUMYARY}

High Efficiency Mist Eliminators (HEME) and High Efficiency Particulate Airfilters (HEPA) are to be used in the Defense Waste Processing Facility (DWPF) to remove volatile and semi-volatile effluents from the off-gases generated during the vitrification process. When removed, these filters arc likely to contain radioactive contaminants, organics, and hazardous materials, which make their disposal by normal methods impractical. Hence, an alternative disposal method is needed.

The alternative disposal method evaluated in this study is dissolution of the filters with caustic and acid solutions. Dissolution converts the waste into an aqueous stream, which can be transferred to the Tank Farm and disposed of by normal means. This process was shown to be effective on a small scale in earlier studies, but the results were not well documented and the studies were not performed on fouled filters.

The previously studied dissolution process, along with some potential improvements, was tested on clean and fouled filter samples. Although the process was effective in breaking down small samples (one inch cubes), its effectiveness diminished for larger sized samples. For larger samples, the process tended to break down the filter elements, but the pieces were not small enough for easy transfer. An experiment imitating the conditions of the Decon Waste Treatment Tank (DWTT), while also not completely successful, produced a particle free solution, with the 24 remaining filter encased in the filter basket.

Though complete dissolution was not achieved for every test condition, filter dissolution utilizing 48 hours of $5 \% \mathrm{NaOH}$ treatment, 96 hours of $5 \% \mathrm{HNO}_{3}$ treatment, and 4 hours of $5 \% \mathrm{NaOH}$ treatment at near boiling temperatures seems to be a viable dissolution process if there is sufficient agitation. A larger scale test using the DWTT processing conditions is recommended.

\section{INTRODUCTION}

The DWPF vitrification process will generate off-gases, which contain significart quantities of radioactive Cs-137, Sr-90, and TRU contaminants. 1 HEME and HEPA filters are used in the off-gas system to remove these contaminants. The HEME is responsible for removing approximately $98 \%$ of the $\mathrm{Sr}-90$ and $83 \%$ of the TRU contaminants, while 
November 23, 1992 HSRC-TR-92-549

the HEPA removes virtualí all of the Cs-137 and approximately $17 \%$ of the TRU contaminants. ${ }^{2}$

These filters will probably need changing on an annual basis, and since the filters contain high levels of contamination, they cannot be disposed of by normal methods. In order to dispose of the filters and minimize solid waste generation, DWPF decided that it would be best to try and break down the filters and send them to the Tank Farm as an aqueous stream.

To achieve this end, a dissolution process using 48 hours of $5 \frac{\mathrm{NaOH}}{\circ}$ treatment, 96 hours of $5 \% \mathrm{HNO}_{3}$ treatment, and a final 4 hours of $5 \% \mathrm{NaOH}$ treatment at near boiling temperatures was developed by J.L. Bransford. ${ }^{3}$ His process was derived from preliminary work done by B.A. Daugherty, who used $5 \% \mathrm{NaOH}$ to dissolve the filters. Daugherty's process was not completely successful because of the soluble and insoluble reaction products that remained in solution. 4 Bransford's experiments proved sufficient on a small scale, but information on the post-digestion solutions and products was not documented.

Analysis of the dissolution products was performed by C. M. Jantzen. She concluded that the complete caustic-acid-caustic dissolution process was necessary because insoluble zeolite reaction products remained after the first caustic treatment, which could only be dissolved by using the acid treatment. She further concluded that only dissolved amorphous silica remained after the acid dissolution step and the final caustic step was only necessary to adjust the $\mathrm{pH}$ for recycle to the Tank Farm. 5

While Bransford's dissolution process was sufficient in breaking down the filters, it was only performed on clean filter elements, and thus the effects of foulants on the filter dissolution process were not known. Recent experience with fouling of the HEME at TNX indicated that organic materials from the hydrolysis of tetraphenylborate could coat the filter elements, possibly making dissolution more difficult, and resulting in difficult to control reactions. 6 The ability to transfer the aqueous waste stream, from a chemical component and physical characteristic standpoint, also had to be proven. Therefore, demonstrations with filter elements which had been exposed to processing conditions were needed.

The scope of this study was to duplicate the previous experiments and determine if the process would effectively dissolve a fouled filter. In addition, the chemical composition and important physical properties of the products of the dissolution were to be documented. Analyses of the components of the dissolution solutions aided in determining how well the filters were dissolved.

In order to meet all the requirements of the task assignment, numerous experiments were performed in this study. A clean HEPA, fouled HEPA, and fouled HEME were obtained for the work. The HEPAs are supplied by Flanders Filters Inc. and are representative of those that will be used 
in the DWPF. The size of the filter fibers range from 0.33 to 10 microns. Their analyzed composition, along with the manufacturer supplied composition, is shown in Table 1. The fouled HEPA was removed from the Integrated DWPF Melter system (IDMS) where it was used during several campaigns.

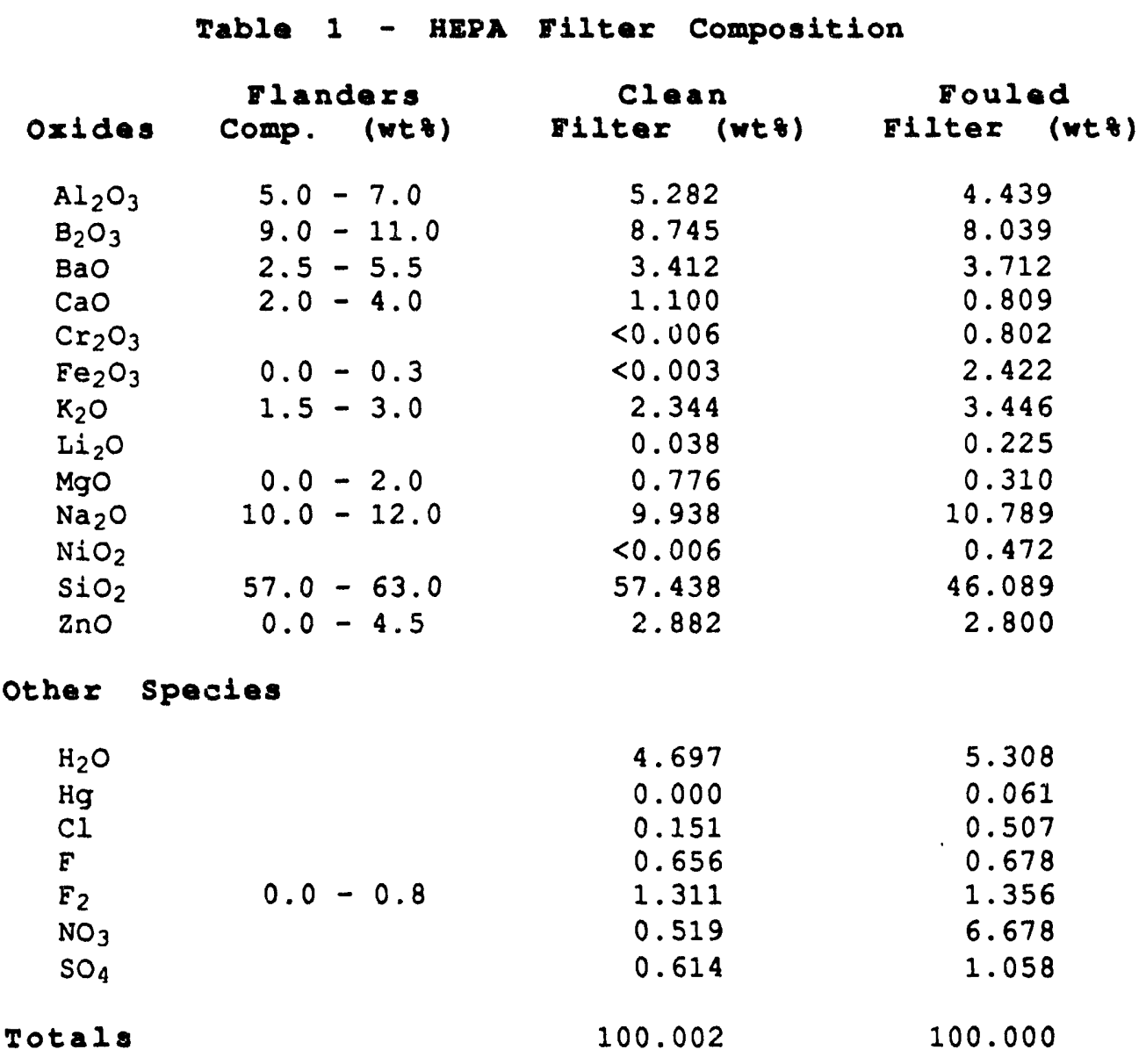

The fouled HEME was supplied by Monsanto Environmental Chemistry and is also representative of the DWPF filters. It is composed of 100 se 7 micron to 20 micron fibers surrounded by a woven mat of 16 micron to 80 micron fibers. The composition was not supplied by Monsanto for proprietary reasons, but its analyzed composition is shown in Table 2 . The HEME used in these experiments and the HEMEs to be used in the DWRF contain less $\mathrm{CaO}$, but more $\mathrm{Na}_{2} \mathrm{O}$ and $\mathrm{K}_{2} \mathrm{O}$ than those studied in Bransford's experiments. It was removed from the IDMS after being located in the Formic Acid Vapor Condenser (FAVC) system. A clean HEME was not obtained for these studies due to the long procurement time and high cost, but it is likely that the fouled HEME will be more difficult to digest. 


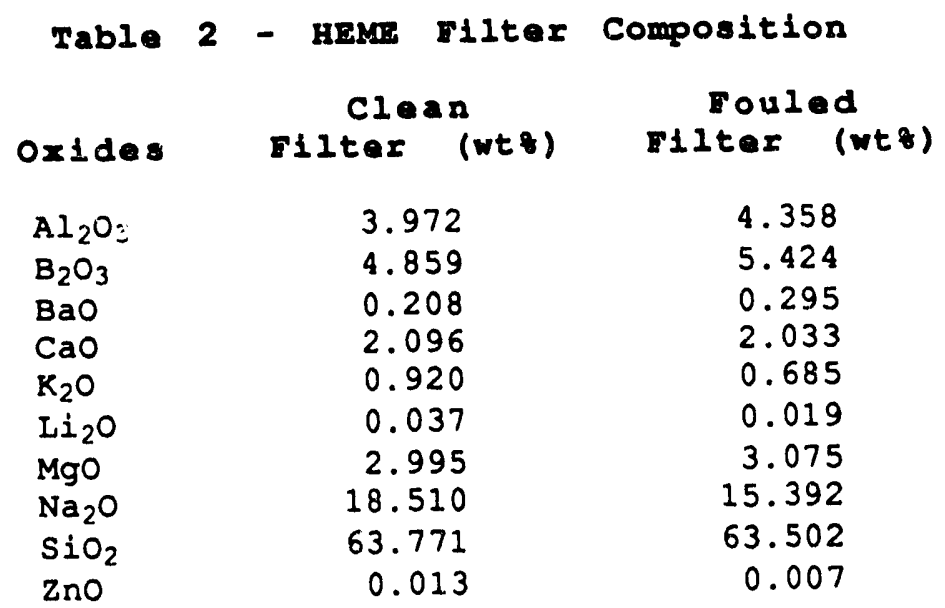

other species

$\begin{array}{lrr}\mathrm{H}_{2} \mathrm{O} & 2.120 & 2.950 \\ \mathrm{Hg} & 0.000 & 0.056 \\ \mathrm{CI} & 0.255 & 0.267 \\ \mathrm{~F} & 0.048 & 0.031 \\ \mathrm{NO}_{3} & <0.300 & 2.578 \\ \mathrm{SO}_{4} & 0.195 & 0.182 \\ \text { Totals } & 99.999 & 99.999\end{array}$

\section{EXPFRIMFNTAL}

All experiments were performed using procedure GTOP-3-055, Revision 0 or $1.7,8$ Deviations from the procedure were noted on the data sheets, which can be found in WSRC-NB-92-39. Solutions were sampled for analyses and physical property determination after each processing step. These analyses are described in WSRC-RD-92-01.9 The viscosity and water loss of the final solutions were recorded, as well as composition of the final solid components.

For ease in recognizing experiments and samples, a sample identification system was developed. The sample number was of the form FDT-XX-Y-Z, where the FDT represents Eilter Dissolution Task, the XX represents the type of filter (CP-Clean HEPA, FP-Fouled HEPA, and FM-Fouled HEME), $Y$ represents the experiment trial number (from each filter), and $Z$ represents the processing step (this applies only to samples, not experiments, the $S$ stands for the remaining solid residue). All dissolution experiments and parameters are identified in Table 3 using this nomenclature. 
Table 3 - Sample Numbers

\section{Caustic-Acid-Caustic Experiments}

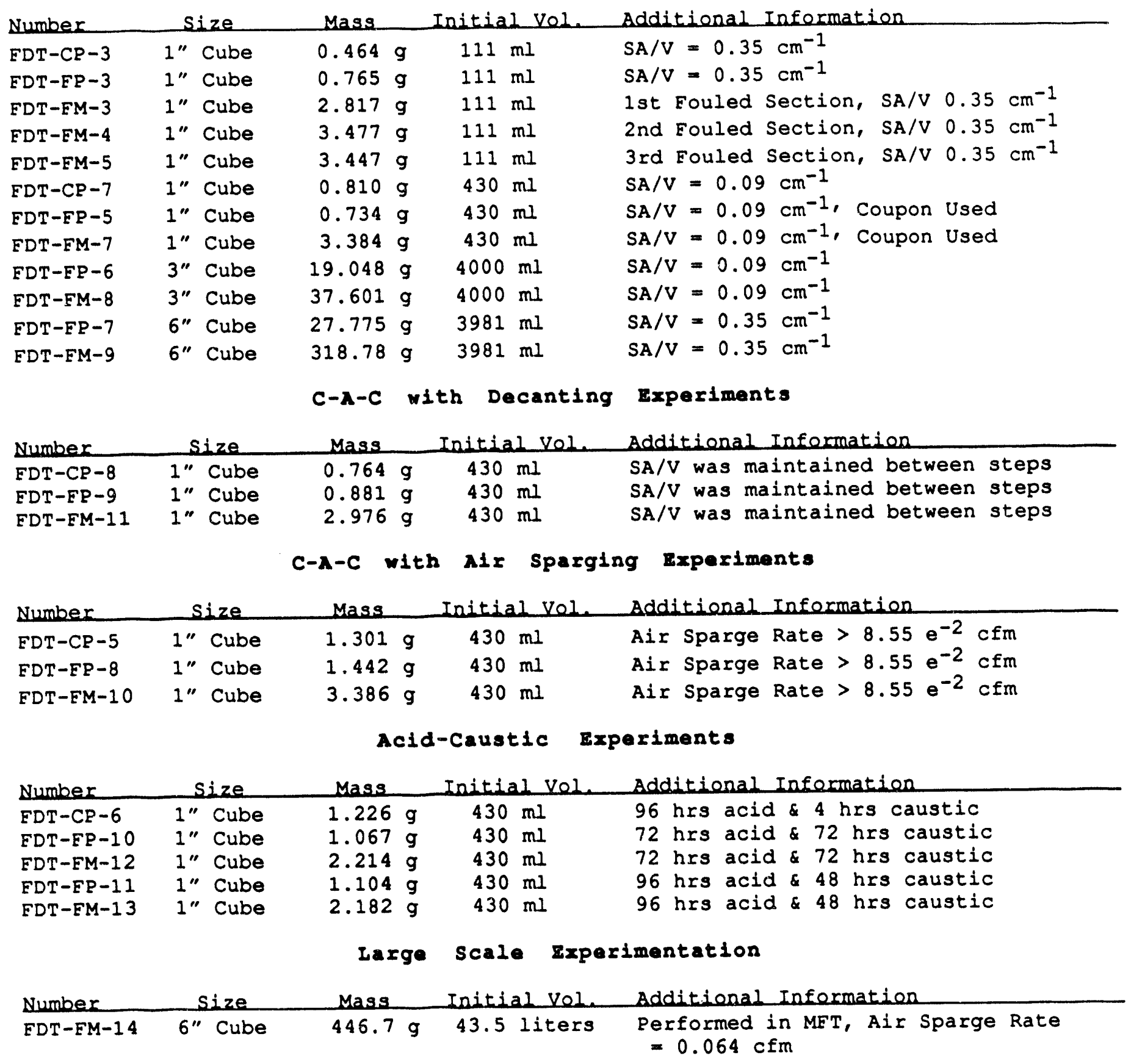

\section{DWTT Mock-up Experiment}

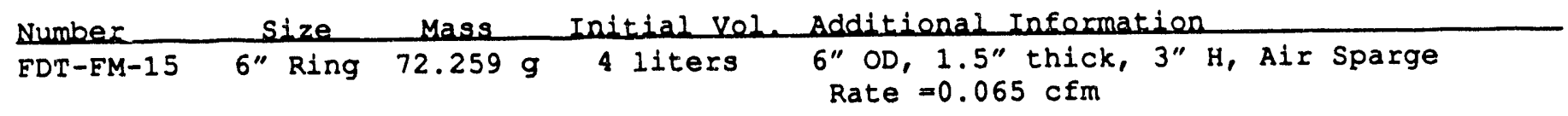




\section{Caustic-Acid-Caustic Dissolutions}

Bransford's dissolution processing conditions of 48 hours of $5 \% \mathrm{NaOH}$ treatment, 96 hours of $58 \mathrm{HNO}_{3}$ treatment, and 4 hours of $58 \mathrm{NaOH}$ treatment were used as the basis for all experiments. This process was tested on one inch, three inch, and six inch cubes of filter element. While the one inch cube tests were performed with all types of filters, the three and six inch tests were only performed with the fouled filters, being that they represented the worst case scenarios. Different sized samples were tested so the scale-up potential could be determined.

Various surface area to volume (SA/V) ratios were tested with Bransford's process so that the smallest amount of dissolution solution needed could be determined to ensure waste minimization. The main two ratios used in the experiments were 0.35 and $0.09 \mathrm{~cm}^{-1}$. The $0.35 \mathrm{~cm}^{-1}$ $\mathrm{SA} / \mathrm{V}$ ratio was based on past leaching experiments and the $0.09 \mathrm{~cm}^{-1} \mathrm{SA} / \mathrm{V}$ ratio was based on Bransford's experiments.

Both stainless steel and teflon vessels were used in the experiments. The purpose was to allow for comparison of the effects of the caustic, acid, and organics on the vessel walls, as well as to help define the species that will dissipate into the solution. Coupons made of $304 \mathrm{~L}$ stainless steel were also used to help determine the extent of corrosion on the metal, so that any precautions necessary for the DWPF could be determined. As mentioned earlier, the DWPE will be using a stainless steel tank, the DWTT, to perform their dissolutions.

\section{Caustic-Acid-Caustic Dissolutions with Decanting}

Decanting was used with Bransford's dissolution process to determine any benefits. The rationale behind this approach was to rid the processing vessel of the saturated solution, so further dissolution would be possible. In these tests, the remaining dissolution solutions were decanted off after each dissolution step.

The decanting experiments were performed on one inch cubes of all filter types, using the $0.09 \mathrm{~cm}^{-1} \mathrm{SA} / \mathrm{V}$ ratio. This ratio was maintained every time solution was added.

\section{Caustic-Acid-Caustic Dissolutions with Air Sparging}

The benefits of air sparging with Bransford's dissolution process were examined. The DWTT does not have the ability to agitate when filters are being dissolved; however, it does have a permanently installed air sparge ring, which can serve as an agitator.

In the lab scale experiments, teflon hosing connected to an air supply line and a flowmeter was used to simulate air sparging. The air sparging experiments were performed on one inch cubes of all filter 
types, using the $0.09 \mathrm{~cm}-1 \mathrm{SA} / \mathrm{V}$ ratio. The tefion vessels were used, and the sparge line was inserted through a septum in the lids.

\section{Acid-Caustic Dissolutions}

Experiments were performed using the acid and final caustic step of Bransford's dissolution process. The benefits to be gained were time and waste minimization. The main purpose of the acid step in Bransford's process, according to Jantzen, was to break down the zeolite products that remained after the initial caustic step; therefore if the acid were strong enough to perform the dissolution alone, then time and waste minimization could be achieved.

These experiments were initially performed on an one inch cube of the clean HEPA for a total of 100 hours, which is equal to the time of the last two steps in Bransford's process. The experiments were later performed on one inch cubes of the fouled HEPA and HEME for 144 hours, which is equal to the duration of Bransiord's process minus the 4 hours required for conversion to a basic solution. The last 4 hours would no longer be necessary since the solution would be basic already.

\section{Effluent Penetration Depth}

A vertical section of the fouled HEME was removed and divided into three sections to determine what effect, if any, the degree of effluent penetration had on the dissolution process. Each section was dissolved using the $0.35 \mathrm{~cm}^{-1} \mathrm{SA} / \mathrm{V}$ ratio in the stainless steel Parr bombs. These experiments were performed at the same time as the caustic-acid-caustic dissolution experiments.

\section{Iarge Scale Dissolution}

In order to ensure that the process would suffice on a larger scale, a dissolution experiment with a six inch cube of the fouled HEME was performed in the 774-A Melter Feed Tank (MFT). The MFT provided adequate space and volume capacity to better simulate the processing conditions of the DWTT.

The SA/V ratio for this experiment was $0.032 \mathrm{~cm}^{-1}$, which is still 10 times less solution than the ratio to be seen in the DWTT. An air sparge tube was also used in this experiment with a flow rate of 0.064 cfm, which is proportional to the flow rate to vessel volume of the DWTT. An immersion heater was used as the heat source for the experiments.

\section{DWTT Mock-up Dissolution}

To more accurately reflect the DWTT dissolution conditions, an experiment was performed with the fouled HEME encased in a stainless steel "basket" and utilizing an alr sparge ring. When the filters are dissolved in the DWTT, they will still be in their filter housings and 
November 23, $1992 \quad 8 \quad$ WSRC-TR-92-549

will be placed in a basket that is lowered into the DWTT. Hence, the effects of having the filter concentrated in one place, where the solution would be not accessible to all sides, had to be studied.

The filter sample for this experiment was not a cube, but rather a 1 1/2" thick, 3" high, and 6" outer diameter ring of filter, reflecting the actual design of the HEME. A $1 / 4$ scale ring air sparger was used to represent the DWTT's sparger. This sparge ring was made of teflon tubing with holes drilled in the tubing, and this in turn was connected to an air supply line. The sparge ring rested on the bottom of the vessel, similar in design to the DWTT. The volume of solution was limited by the vessel volume, the $\mathrm{SA} / \mathrm{V}$ ratio was $0.205 \mathrm{~cm}^{-1}$.

\section{Triton}

The effects of the chemical surfactant Triton on cleaning and dissolving the fouled HEME filter were studied. This chemical, when used with $\mathrm{KOH}$, had proven satisfactory in destroying organics in some previous TNX experiments.

Experiments were performed on small samples of the HEME filter using 3000 ppm Triton with $5 \% \mathrm{NaOH}$ and $5 \% \mathrm{KOH}$ in beakers on a hot plate. The solution and remaining filter for each sample were chemically analyzed. In addition, the final weight loss for each sample was calculated to see how well the solutions dissolved the filters.

\section{BDSUITS AND DISCUSSION}

The effectiveness of the dissolutions was determined from how well the fibers were dissolved. Additional insight was provided from the analyses of the dissolution solutions and the dissolution products that remained. Analyses of the remaining filter products were only performed, when a sizeable quantity of filter remained.

When Bransford's products were analyzed, Jantzen found that the residue remaining after the first caustic step was a Na-zeolite of the Linde $B_{1}$ type, with a composition of $0.95 \mathrm{Na}_{2} \mathrm{O} \cdot \mathrm{Al}_{2} \mathrm{O}_{3} \cdot 3.35 \mathrm{SiO}_{2} \cdot 4.79 \mathrm{H}_{2} \mathrm{O}$. Zeolites of this structure tend to incorporate $\mathrm{Ca}, \mathrm{K}$, and $\mathrm{Mg}$; thus, by monitoring their presence in the dissolution solution, the completeness of the acid dissolution could be monitored. Jantzen noted that this zeolite was completely dissolved by the end of the acid step, and all that remained was an amorphous silicate based gel. After the final four hours of caustic treatment, the main crystaline materials detected were $\mathrm{NaNO}_{3}$ and $\mathrm{NaNO}_{2}$, indicating thorough breakdown of the filter material.5

The appearance of Bransford's observed products, as well as the filter material components, were monitored in these studies for confirmation of filter dissolution. 


\section{Caustic-Acid-Caustic Dissolutions}

Bransford's reference process proved effective on dissolving one inch cubes of the clean HEPA (FDT-CP-7), fouled HEPA (EDT-FP-5), and the fouled HEME (FDT-FM-7) using a $S A / V$ ratio of $0.09 \mathrm{~cm}^{-1}$. The first caustic treatment caused the elements to break down into much smaller pieces, which were dissolved even further by the conclusion of the acid treatment. Only a few very small filter particles remained settled at the bottom of the vessels by the end of the tests.

Bransford's process, however, did not dissolve as completely when a $0.35 \mathrm{~cm}^{-1} \mathrm{SA} / \mathrm{V}$ ratio was used. The HEPA (FDT-CP-3 and FDT-FP-3) filter cubes dissolved more than the HEME (FDT-FM-3) did, but pieces of the filters remained undissolved in all experiments at this ratio.

Though the smaller volume of solution failed to entirely dissolve the filter elements, this does not present an obstacle to the DWPF, since the DWTT will require a much smaller SA/V ratio. Approximately 6,000 gallons of solution will be required to operate the DWTT when dissolving the filters, due to the coil coverage requirements. This equates to a $\mathrm{SA} / \mathrm{V}$ ratio of rough.ly $0.0032 \mathrm{~cm}^{-1}$.

The caustic-acid-caustic dissolution process was further tested on three inch cube samples of the fouled HEPA (FDT- FP-6) and HEME (FDT-FM-8) filter using the $0.09 \mathrm{~cm}^{-1} \mathrm{SA} / \mathrm{V}$ ratio. These tests did not prove as successful as the one inch tests. Large pieces of the filter remained intact and were found floating on the solution surface, while small pieces had settled to the bottom of the vessel by the end of the experiment. Stirring between the steps did seem to help in the fouled HEME dissolution, but it was not significant enough to completely break down the filter.

To finish the dissolution scale-up experiments, the process was attempted on six inch cubes of the fouled HEPA (FDT-FP-7) and HEME (FDT-FM-9). A SA/V ratio of $0.35 \mathrm{~cm}^{-1}$ was utilized, due to vessel volume limitations. Both attempts resulted in large pieces of the filter remaining intact, with the large pieces once again floating on the surface. The solutions for each test were very saturated. The one important difference to note between the two filter dissolutions was the appearance of hard agglomerated matter during the HEME acid dissolution step. This substance conformed to the vessel walls and was difficult to break apart. It can probably be attributed to the small volume of the dissolution vessel and the small amount of dissolution solution available to effectively break down the filter. Stirring between the steps helped to break the large pieces into smaller pieces, but it did not completely break down the elements.

The chemical analyses results of the caustic-acid-caustic dissolution solutions are given in Attachment 1. The chemical analyses results for FDT-CP-7-1 indicate that the filter elements had started to dissolve during the initial caustic dissolution, as evidenced by the appearance 
of $\mathrm{Zn}, \mathrm{Al}, \mathrm{B}$, and $\mathrm{SI}$ in the solution. Results for FDT-CP-7-2 show that more of these elements, along with $\mathrm{Ca}, \mathrm{Mg}, \mathrm{K}$, and $\mathrm{Ba}$, were dissolved into solution during the acid treatment. This supports Jantzen's theory that the $\mathrm{Ca}$ and $\mathrm{Mg}$ that were incorporated in the zeolites are released in the acid step. The final elemental concentration results, EDT-CP-73 , suggest that the primary solution components remaining are $\mathrm{Na}$ and $\mathrm{NO}_{3}$, which once again supports Jantzen's theory.

All of the elemental analyses for FDT-FP-5 and FDT-FM-7 were not available because of problems that occurred when the samples were analyzed. The results available do reflect the presence of the major filter components in the dissolution solutions, as seen with the clean HEPA filter cube. An observation from the fouled filter experiments not seen in the clean filter experiment was the behavior of mercury during dissolution. Most of the mercury dissolved from the filter during the acid dissolution step, as attested by the increase in mercury concentration in solution. By the completion of the tests, a large portion of the released mercury had evaporated off, which was verified by the decrease in mercury concentration of the final solution. This is important considering the toxicity of mercury. Overall, the fouled filter experiments had greater final concentrations of the filter components than the ones for the clean HEPA under the same conditions, but the physical evidence from the tests indicate that the filter cubes were broken down enough to be transferrable.

The XRD results indicate mostly the presence of sodium compounds, and not zeolites as seen in past experiments. The SEM results, however, indicate that the components of the zeolites were in solution, as well as large quantities of the filter material. The SEM results also support most of the findings of the XRD and chemical composition analyses.

The $0.35 \mathrm{~cm}^{-1} \mathrm{SA} / \mathrm{V}$ ratio dissolution results were similar to the $0.09 \mathrm{~cm}^{-1} \mathrm{SA} / \mathrm{V}$ ratio results, in that the largest amounts of filter components were released during the acid dissolution step. However, in general, the concentrations of the filter components in solution were greater during the $0.35 \mathrm{~cm}^{-1} \mathrm{SA} / \mathrm{V}$ ratio tests. Since the concentrations were higher, it would seem that the $0.35 \mathrm{~cm}^{-1} \mathrm{SA} / \mathrm{V}$ ratio test was more effective, but this was not the case. The most probable explanation is that the $0.35 \mathrm{~cm}^{-1} \mathrm{SA} / \mathrm{V}$ ratio solutions were too saturated to dissolve the filter any further.

The XRD results at this ratio did not indicate the presence of sodium silicate as seen at the $0.09 \mathrm{~cm}^{-1} \mathrm{SA} / \mathrm{V}$ ratio, which indicates that the dissolution was not as effective. On the other hand, the SEM results revealed that some of these sodium compounds were present, along with components of the filter, but in great of quantities as the $0.09 \mathrm{~cm}^{-1}$ $\mathrm{SA} / \mathrm{V}$ ratio.

For the three inch cube tests, some of the data for FDT-EP- 6 was not available, once again, due to problems during analyses. In general, the results indicate the same dissolution trend as mentioned above; however, 
November 23, 1992 WSRC-TR-92-549

large quantities of the filter components remained at the end of dissolution, as can be seen from the high $B, S i, K$, and $A l$ concentrations. Analyses of the remaining solid products revealed that most of the major filter components had not been dissolved.

When larger quantities of the filter were dissolved, more complex products appeared in the XRD and SEM results. The same basic compounds were identified as in the one inch cube tests, but compounds with more than two species began to appear. Less of the filter components were released freely into solution and $\mathrm{CeF}_{3}$ started to form.

Review of the analytical results for the six inch cube tests lead to the same conclusions as those of the three inch tests. The largest dissolutions occurred during the second processing steps, and considerable amounts of the filters remained undissolved at completion of the experiments, as verified by the solid residue analyses. The major difference in the XRD and SEM results was that the six inch HEPA sample tended to form barium compounds as opposed to the more complex compounds seen : 2 r the six inch HEME tests and hoth three inch filter tests. The SEM results supported the XRD findings.

The corrosion potential of Bransford's dissolution process on stainless steel was investigated. The Materials Technology section (MTS) examined the stainless steel parr bombs used in the first experiments and the 304 I coupons suspended in the tefion vessels and did not discover any signs of corrosion. From the literature search pezformed by MTS, they concluded that $304 \mathrm{~L}$ was not susceptible to stress corrosion cracking in 5 wt: $\mathrm{NaOH}$ or 5 wt $\mathrm{HNO}_{3}$ at boiling temperatures.

\section{Caustic-Acid-Caustic Dissolutions with Decanting}

Decanting proved to be an effective method for dissolving the filter elements. The tests proved as successful as did caustic-acid-caustic dissolution alone. Very little, if any, of the filters remained intact by the end of dissolution. However, when using decanting, more solution is required for the overall process. Since a main goal of all waste management activities is to minimize the waste produced, this consideration must be taken into account when deciding on the best method for dissolution.

The analytical results for the decanting experiments are contained in Attachment 2 . When the results from the clean filter decanting experiment (FDT-CP-8) are compared to the normal dissolution clean filter results (FDT-CP-7), the results from the first processing step are similar, as are the results from the second processing step with a few exceptions. Decanting dissolved less $\mathrm{Zn}, \mathrm{Al}, \mathrm{B}, \mathrm{Si}$, and $\mathrm{K}$ then the normal processing did during the second step. On account of this, the decanting final solution contained greater concentrations of the filter components. The final $\mathrm{Na}$ and $\mathrm{NO}_{3}$ levels were much lower for the regular processing also. 
Due to the fact that not all of the results are available for the fouled filter normal dissolutions, direct comparison to the decanting experiments is difficult. However, from the data that is available, the results indicate that the decanting experiments dissolved most of the filter components by the end of the dissolutions, whereas the normal processing final solutions still contained large concentrations of the filter components.

The combination of the decanting results from the clean and fouled filter experiments are not consistent when compared to the normal processing results. While results from the clean filter decanting experiments seemed worse than the normal processing results, the results from the fouled filter decanting experiments seemed much better. A possible explanation of this behavior might be that the processing solutions for the fouled filter experiments become saturated with the organics and other foulants and are unable to dissolve the filters further. By changing the solutions, as is done in decanting, more of the solution is free to break down the filter elements.

The XRD results were consistent for all of the decanting experiments. Sodium carbonate and silicate were identified in the caustic solutions, while sodium nitrate was identified in the acid solutions. The SEM results support the presence of these components as well as the filter materials identified in the chemical analyses.

\section{Caustic-Acid-Caustic Dissolutions with Air Sparging}

Experiments performed with air sparging proved very effective in breaking down the one inch cube samples. None of the filter elements remained intact at the end of the process and very little appeared in solution. However, one draw-back to this method was that the volume had to be constantly monitored, due to the evaporation from the dissolution vessels that occurred.

While these tests were successful, the flow rate to vessel volume ratio of the teflon vessels $(0.327 \mathrm{cfm} / \mathrm{gal})$ was much greater than the flow rate to vessel volume ratio of the DWTT $(0.0022 \mathrm{cfm} / \mathrm{gal})$. The larger ratio present in the teflon vessels would make dissolution much simpler, so this factor must be considered when determining the effectiveness of air sparging.

The analytical results for the air sparging experiments are contained in Attachment 3 . Chemical analyses results for the first dissolution solutions are not available because most of the liquid had evaporated out of the vessels. For the clean HEPA with air sparging (FDT-CP-5), the acid dissolution step resulted in smaller amounts of filter components in solution than with the normal dissolution processing, with the exception of $\mathrm{B}, \mathrm{Na}$, and $\mathrm{Si}$. Whereas the opposite effect held true for the final solution of the air sparging experiments, much more of the filter components remained in solution than with the normal process. These result's do not support the actual physical evidence from the 
experiment, since hardly any of the filter remained by the end of the experiment using air sparging.

Once again, the results for the fouled filter experiments (FDT-FP-8 and FDT-FM-10) seemed to be opposite of the clean filter results. When comparing the final solutions of the fouled filter air sparging experiments to the fouled filter normal processing experiments, the normal processing final solutions contained larger concentrations of the filter components in solution, with the exception of $\mathrm{Na}, \mathrm{B}, \mathrm{K}$, and $\mathrm{Si}$. The solid residue that did remain still contained some quantities of the filter components, but it was not a significant amount.

Sodium carbonate was easily identified in all of the XRD results for the air sparging experiments, perhaps due to the air that was able to get into the vessel. Sodium silicate was also identified, which indicates dissolution of the filter. The SEM results supported both the XRD and chemical analyses results.

\section{Acid-Caustic Dissolutions}

The initial acid-caustic dissolution was performed on a clean HEPA. While dissolution did not appear to occur until the caustic was added and pieces of the filter still remained at the end of the test, analytical results indicated that the filter had begun to dissolve during the acid test, and the releases were equivalent to those experienced in the caustic-acid-caustic dissolution process. This is consistent with Jantzen's results. 5

Since the initial test duration was only 100 hours and the filter element had shown some signs of dissolution after the 4 hours of caustic treatment, it was decided to try the process for 144 hours on fouled filters. One set of tests consisted of 96 hours of acid and then 48 hours of caustic treatment, while the other set consisted of 72 hours of acid and then 72 hours of caustic treatment. For both time durations, the results were the same. The fouled HEPA elements had dissolved slightly and then settled to the bottom, while the undissolved pieces remained floating on the surface. The fouled HEME loose fibers had completely dissolved, but the woven fibers remained undissolved. Once again, evidence of break-down appeared in the analytical results.

The analytical results for the acid-caustic dissolutions are given in Attachment 4. For the clean HEPA dissolution (FDT-CP-6), the data in Attachment 4 indicates that a significant amount of the filter had dissolved in the acid step. These concentration numbers were roughly equivalent to the sum of the element concentrations for the first two steps of the normal clean HEPA filter dissolution (FDT-CP-7). However, the difference in dissolution effectiveness is apparent when the final solution concentrations are compared. The filter component concentrations $(\mathrm{Z} n, \mathrm{Al}, \mathrm{Ba}, \mathrm{B}, \mathrm{K}$, and $\mathrm{Si})$ for $\mathrm{EDT}-\mathrm{CP}-6$ were much higher than those of FDT-CP-7. In addition, the $\mathrm{Na}$ and $\mathrm{NO}_{3}$ levels were higher in the final solutions. The effectiveness of dissolving the Na portion 
of the filter could not be determined based on a strict comparison since $\mathrm{NaOH}$ is used in normal processing and this biased the $\mathrm{Na}$ concentration.

For the fouled filter experiments with acid-caustic dissolution, the elemental concentration results do not display much of a difference between the different times of acid-caustic dissolution. The physical results also support this, since no difference was seen between the amount of filter that was dissolved for the 72-72 and the 96-48 hour tests.

When compared to the normal dissolutions, the two filters portrayed different behaviors. The fouled HEPA experiments (FDT-EP-10 and -11) retained larger concentrations of the filter components in the final solution, yet the fouled HEME experiments (FDT-FM-12 and -13) dissolved more of the filter components than the normal processing method. The $\mathrm{Cl}, \mathrm{Na}$, and $\mathrm{NO}_{3}$ levels were much higher for the acid-caustic dissolutions for both filter types than in the normal process.

XRD results for all acid-caustic dissolutions revealed the presence of sodium nitrate in the first solutions. In fact, only the clean HEPA (FDT-CP-6) and the 72-72 hour fouled HEPA (FDT-FP-10) initial solutions indicated the existence of any other compounds. The remaining solutions and final products exhibited the same components. The SEM results supported the XRD and chemical analyses results.

The original intent of this process was for waste and time minimization. While it was shown that waste would be minimized, due to omitting the extra dissolution step, time would not be because of the extra time needed to completely dissolve the filters. Even after the extended time period tests, the results were not good enough to justify recommendation of this process.

\section{Effluent Penetration Depth}

The degree of penetration of effluents seemed to have no effect on the dissolution process. None of the sections tested dissolved any more than the others. All physical characteristics of the final solutions were approximately the same. The only difference present during processing was the colors of the solutions, perhaps indicating the existence of different organics.

The analytical results are presented in Attachment 5 for all 3 sections of the HEME filter. In general, the outermost section of the filter (FDT-FM-3) showed the smallest concentrations of elements and the innermost section (FDT-FM-5) showed the highest concentrations of elements in the solutions. The variation amongst the concentrations was not significant, but it was enough to be noticeable. We are not sure as to which end of the filter the vertical section of filter element was removed from, since we did not know which way the filter was placed in the FAVC system. From the results, it would appear that what we are calling the inner section (FDT-FM-5) was located closest to the off-gas in-take. In either case, the amount of dissolution on the filter 
Novamber 23, 1992 15 WSRC-TR-92-549

elements was approximately the same, so it does not appear that the effluent penetration had an effect on dissolution.

From comparison of the XRD results, the same conclusion can be drawn. The compounds identified were practically the same with the exception of the sodium nitrate identified in FDT-FM-3, as opposed to the potassium calcium aluminum silicate hydrate identified in FDT-FM-4 and -5 . The SEM results tended to confirm the findings of the XRD and chemical analyses. The major difference between the results was the appearance of sulfides in FDT-EM-4 and -5 .

\section{Large Scale Dissolutions}

The six inch cube experiments performed in the MFT using an air sparge tube proved very unsuccessful. Only the pieces of filter located near the air sparge tube dissolved. The remaining filter was as intact as when it was first put in the solution and appeared floating on the solution surface. These results led to the necessity of an actual DWTT Mock-up dissolution.

Analytical results fo: the large scale dissolution experiment (FDT-FM-14) are presented in Attachment 6. The elemental concentrations were not indicative of an effective dissolution. The concentrations for the second processing step should have been much greater, since this is the step where most of the filter components are dissolved into solution. In addition, the final elemental concentrations should have been much lower, since the filter and reaction products should be dissolved by this point. Theoretically, this experiment should have been more successful than the fouled HEME six inch cube experiment without air sparging (FDT-FM-9) because a larger tank and solution volume were used, along with air sparging; however, this was not the case.

The XRD results are consistent with other experiments; however, the SEM results point out that the filter materials did not appear until later in the process. They also indicate that a large portion of the filter material remained in the final product.

\section{DWTT Mock-up Dissolutions}

The tests performed with the DWTT simulated sparger were much more successful than the six inch cube study performed with the air sparge line. Approximately $76 \%$ of the filter dissolved and the remainder stayed in the "basket". A peculiar observation to note from this experiment was that the filter seemed to dissolve most during the last 4 hours of treatment; however, since the mass loss was not measured after each processing step, this notion cannct be substantiated. Due to the fact that the undissolved filter was still in the "basket", the resulting solution was essentially free of particles. Even though this experiment was not a total success, important insight into dissolution conditions was olutained. 
Results from the analyses of the dissolution solutions for the mock-up experiment are presented in Attachment 7. The results indicate that the filter had begun to dissolve during the first step of dissolution, as substantiated by the amount of $A l, B, S i$, and $K$ that had dissolved into the solution. The second step further dissolved the filter and released the $\mathrm{Mg}$ and $\mathrm{Ca}$ that had been incorporated in the first step, as attested to from the concentrations determined. However, the analyses of the final solution irdicated that a substantial part of the filter components still remained in solution, and the analyses of the solid residue also indicated that a substantial part of the filter components had not been dissolved.

XRD results for this test revealed the expected compounds (sodium silicate, carbonate, and nitrate), as well as sodium hydroxide and barium nitrate. The fact that sodium hydroxide was able to be identified indicates that a large portion of the first dissolution solution remained unreacted; thus, maybe the reason why the last caustic step dissolved the filter further. SEM results for this test are not available.

\section{Triton Tests}

The small scale tests that were performed with Triton proved nonbeneficial. While the HEME filter sample did dissolve more in the Triton laced 5\% $\mathrm{NaOH}$ (Sample \#2) than the pure 5\% $\mathrm{NaOH}$ (Sample \#1), chemical analyses results did not show a large difference in the amount of the elements released into solution or the elements remaining in the filter. The attempts with Triton laced 5\% $\mathrm{KOH}$ (Sample \#3) proved even less effective. Not only did less of the filter dissolve, but the releases were even smaller. The concentrations of the elements in solution (in $\mathrm{ppm}$ ) and the composition of the remaining filter (in wto) are presented in Table 5.

Table 5 - Triton Tast Results

$\begin{array}{lrc}\text { Element } & \begin{array}{c}\text { Sampla } \\ \text { Solution }\end{array} & \begin{array}{c}\text { Fiter } \\ \text { El }\end{array} \\ \text { Al } & 217.900 & 0.518 \\ \mathrm{~B} & 251.780 & 0.054 \\ \mathrm{Ba} & 3.415 & 0.044 \\ \mathrm{Ca} & 0.581 & 1.739 \\ \mathrm{Cr} & <0.364 & 0.007 \\ \mathrm{Fe} & 0.713 & 0.063 \\ \mathrm{Hg} & 3.019 & \mathrm{~N} / \mathrm{A} \\ \mathrm{K} & 99.598 & 0.131 \\ \mathrm{Mg} & 0.174 & 1.057 \\ \mathrm{Na} & 51295 & \mathrm{~N} / \mathrm{A} \\ \mathrm{Na} \text { (AA) } & 61648 & 10.805 \\ \mathrm{Si} & 3943.7 & 10.827 \\ \mathrm{Zn} & 6.345 & 0.148\end{array}$

NeIght Ioss
$29.52 \%$

$\begin{array}{cc}\text { Sample } & \$ 2 \\ \text { solution } & \text { Filtar } \\ & \\ 217.320 & 0.736 \\ 262.930 & 0.043 \\ 5.667 & 0.135 \\ 0.610 & 2.548 \\ 0.430 & 0.007 \\ 0.641 & 0.125 \\ 2.519 & \text { N/A } \\ 102.696 & 0.129 \\ 0.033 & 1.642 \\ 50119 & \mathrm{~N} / \mathrm{A} \\ 52071 & 16.523 \\ 4179.9 & 8.879 \\ 20.739 & 0.149\end{array}$

32.718

$\begin{array}{cc}\text { Sample } & \# 3 \\ \text { Solution } & \text { Eilter } \\ & \\ 175.790 & 0.592 \\ 201.450 & 0.060 \\ 2.736 & 0.014 \\ 1.749 & 2.312 \\ <0.364 & <0.004 \\ <0.182 & 0.264 \\ \text { N/A } & \text { N/A } \\ \text { N/A } & \text { N/A } \\ 0.028 & 1.410 \\ 1261.5 & 3.840 \\ \text { N/A } & \text { N/A } \\ 3090.2 & 20.438 \\ 7.027 & 0.135\end{array}$

$22.90 \%$ 
The benefits of using Triton were not realized in these experiments, therefore it is not recommended that this chemical be used in helping to clean the filters. In addition, some very violent reactions were experienced when the temperatures of the Triton laced solutions rose above $80^{\circ} \mathrm{C}$.

\section{concrustons}

The experiments performed in this study, though not completely successful, have provided insight as to a dissolution process that may be effective on dissolving the DWPF's HEME and HEPA filters. The dissolution process developed by Bransford of 48 hours of $58 \mathrm{NaOH}$ treatment, 96 hours of $5 \%$ NO3 treatment, and 4 hours of $5 \% \mathrm{NaOH}$ treatment exhibited limited success. While the process worked well on dissolving one inch cubes of filter, it was not as successful on larger sized samples. However, with the appropriate processing conditions, namely air sparging, the dissolution process proved more effective.

Even though the current tests were not as successful as the experiments performed by Bransford, the analytical results reflected some similarities. Zeolite was not detected in the XRD results as with Bransford's experiments, but their presence was indicated in the SEM results. The dissolution solutions, however, contained the elements necessary to substantiate Bransford's and Jantzen's ideas on what is occurring during the dissolution process. In the successful experiments, dissolution of the major components of the filter began in the first step, the second step further dissolved these components along with releasing the $\mathrm{Ca}$ and $\mathrm{Mg}$ that was believed to be incorporated in the first step, and the final step dissolved anything else that was remaining, so that the only thing remaining in solution was trace quantities of the filter components.

Based on the findings obtained thus far, it is our suggestion that a larger scale experiment be performed using the DWTT operating parameters and conditions. The results of this experiment should ensure that the process is effective in breaking down the fouled filters, before recommending the alternative disposal method to the DWPF.

Organic analyses of the filters and the dissolution solutions and products was not available at this time. Once the samples can be analyzed, the results will be issued in a separate document. The downstream effects of the final dissolution solutions were also not determined, since the transfer criteria for the DWPF to the Tank Farm have not been adequately established. Upon establishment of these criteria, the effects will be determined and a separate report will be issued. 


\section{ACKNOKIEDGEMFNTS}

I would like to thank C. M. Jantzen for her assistance in locating the background material related to the previously performed dissolution work and for her help in setting up the studies in this experiment. I would also like to thank M. K. Andrews, I. L. Cotney, and T. O. Burckhalter for their help in preparing the 774-A Melter Feed Tank for me to use in this study. Lastly, I wish to thank the members of the Analytical Development section for their support with all of the analyses required.

\section{BFERRENCES}

1. L. F. Landon, "Estimated Radionuclide Content of solid Wastes: Defense Waste Processing Facility," DPST-85-833, Revision 1, (October 3, 1983).

2. B. A. Daugherty, "Dissolution of HEPA and HaME Filtration Media," Draft DPSTD (Never issued).

3. A. R. Greening, Memorandum to W. E. Guenther, "Dissolution of Hinke and BEPA Filters," (March 13, 1985).

4. B. A. Daugherty, "Dissolution of BrRA and BEME riltration Media," DPST-84-376 (April 5, 1984)

5. C. M. Jantzen, "summary and status of BEME/HEPA Filter Dissolution for DFRE (Technology Issue 10.1)," WSRC-89-533 (July 4, 1989).

6. M. J. Plodinec, "Dissolution of HEM and HEPA Filter Elements: Task Assignment," WSRC-RP-92-72 (January 27, 1992).

7. GTOP-3-055, Dissolution of HEME and HEPA Filter Elements, Rev. 0, 2/24/92, C. A. Cicero. (Glass Technology Procedure Manual, L13-1)

8. GTOP-3-055, Dissolution of HEME and HEPA Filter Elements, Rev. 1 , $4 / 6 / 92$, C. A. Cicero. (Glass Technology Procedure Manual, L13-1)

9. C. A. Cicero, "Analytical study Plan: MEME and HEPA Filter Element Dissolution Task," WSRC-RD-92-01 (April 10, 1992). 


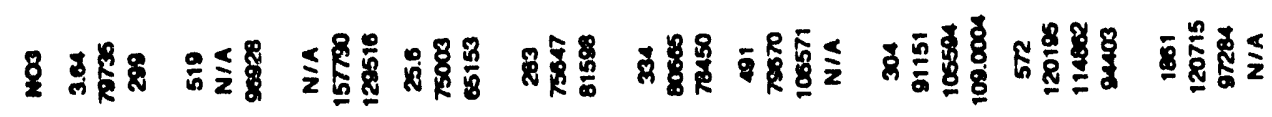

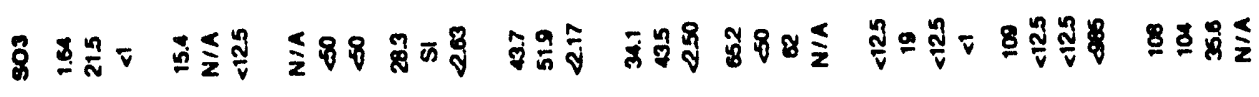

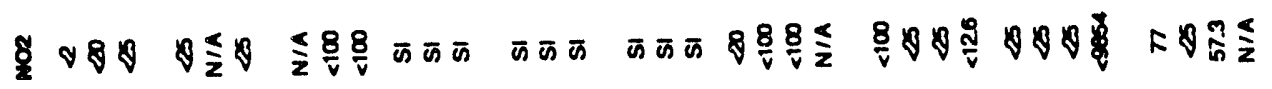

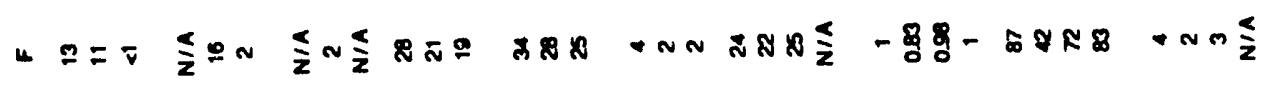

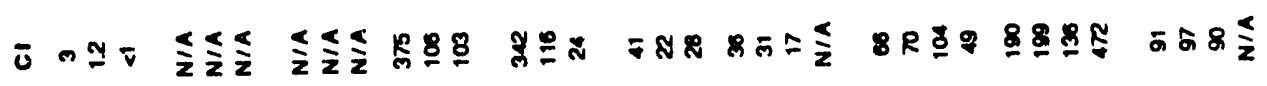

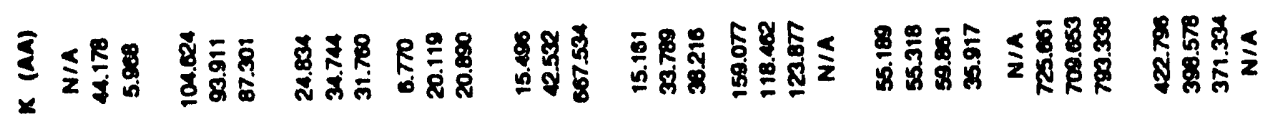

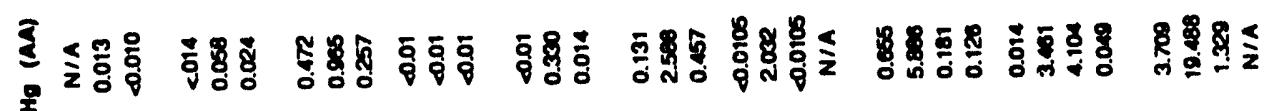

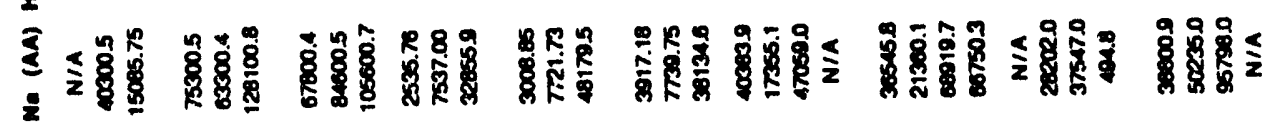

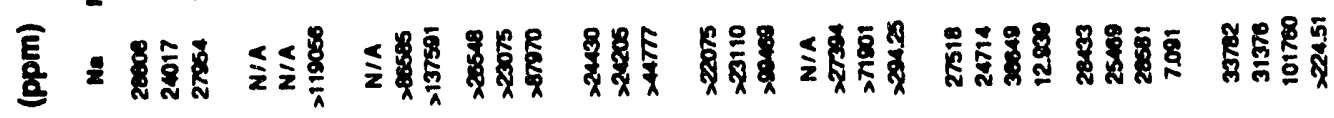

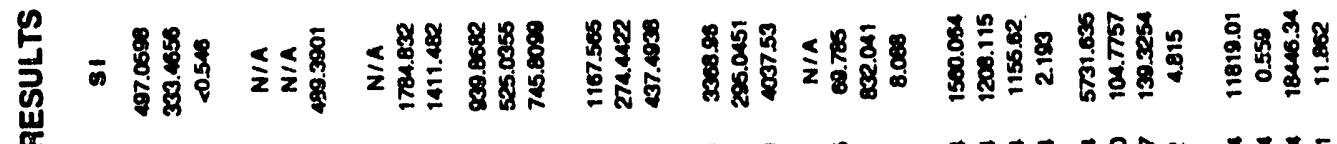

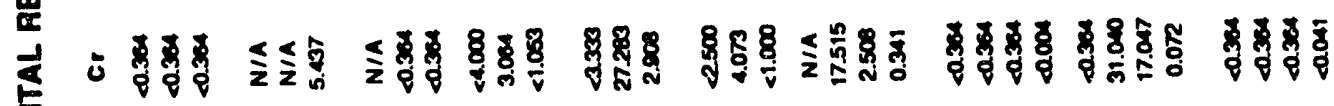

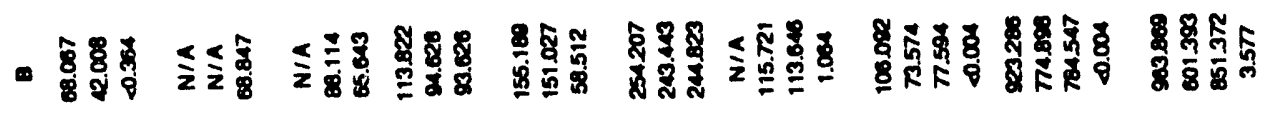

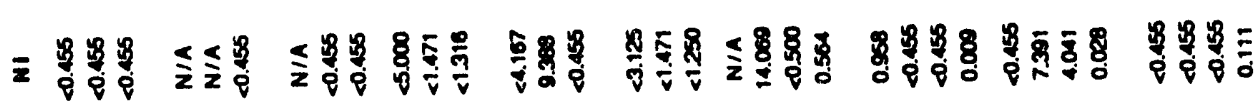

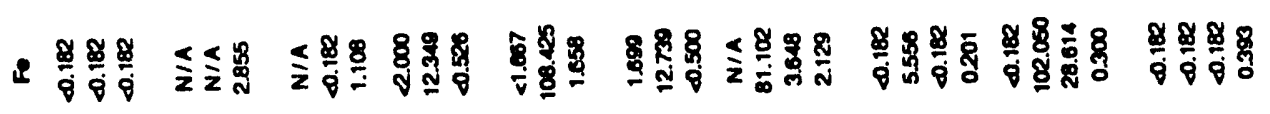

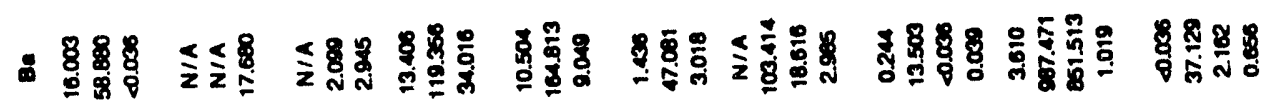

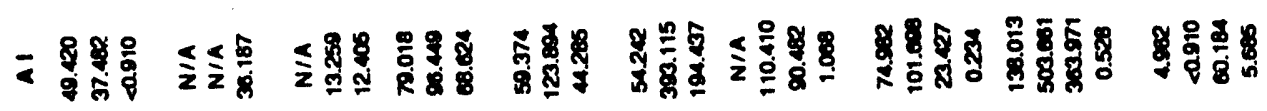

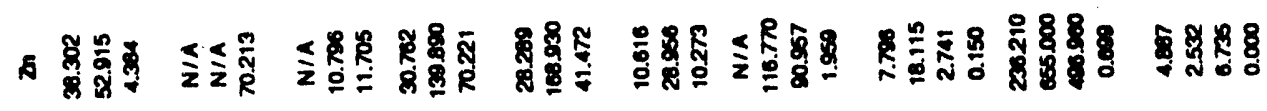

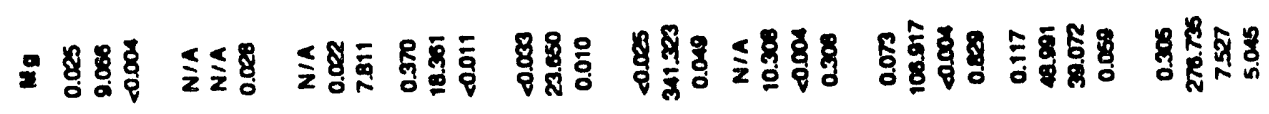

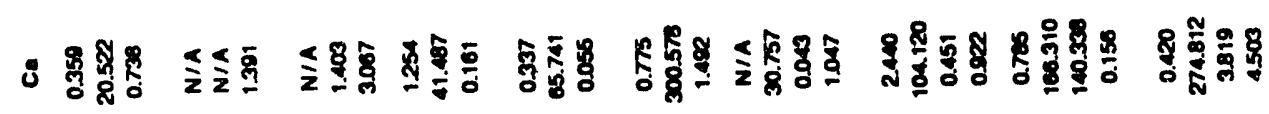

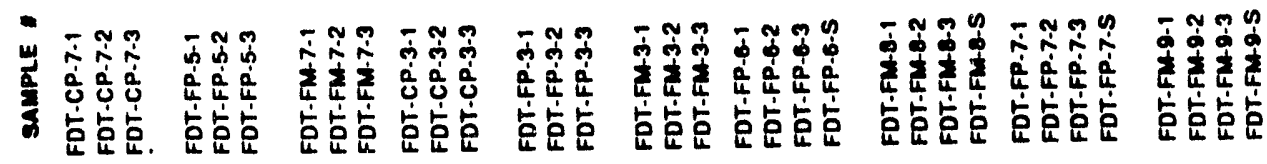




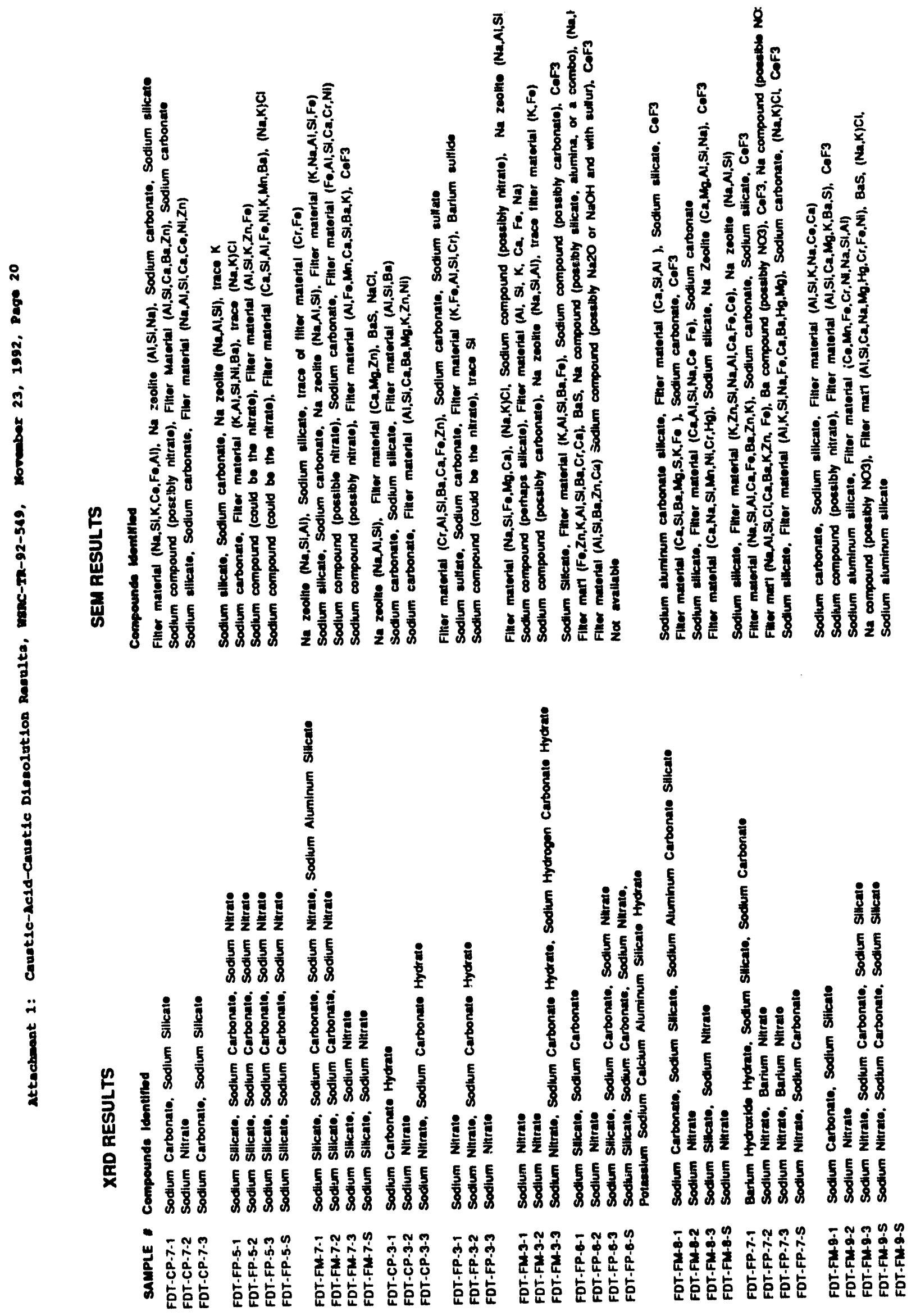




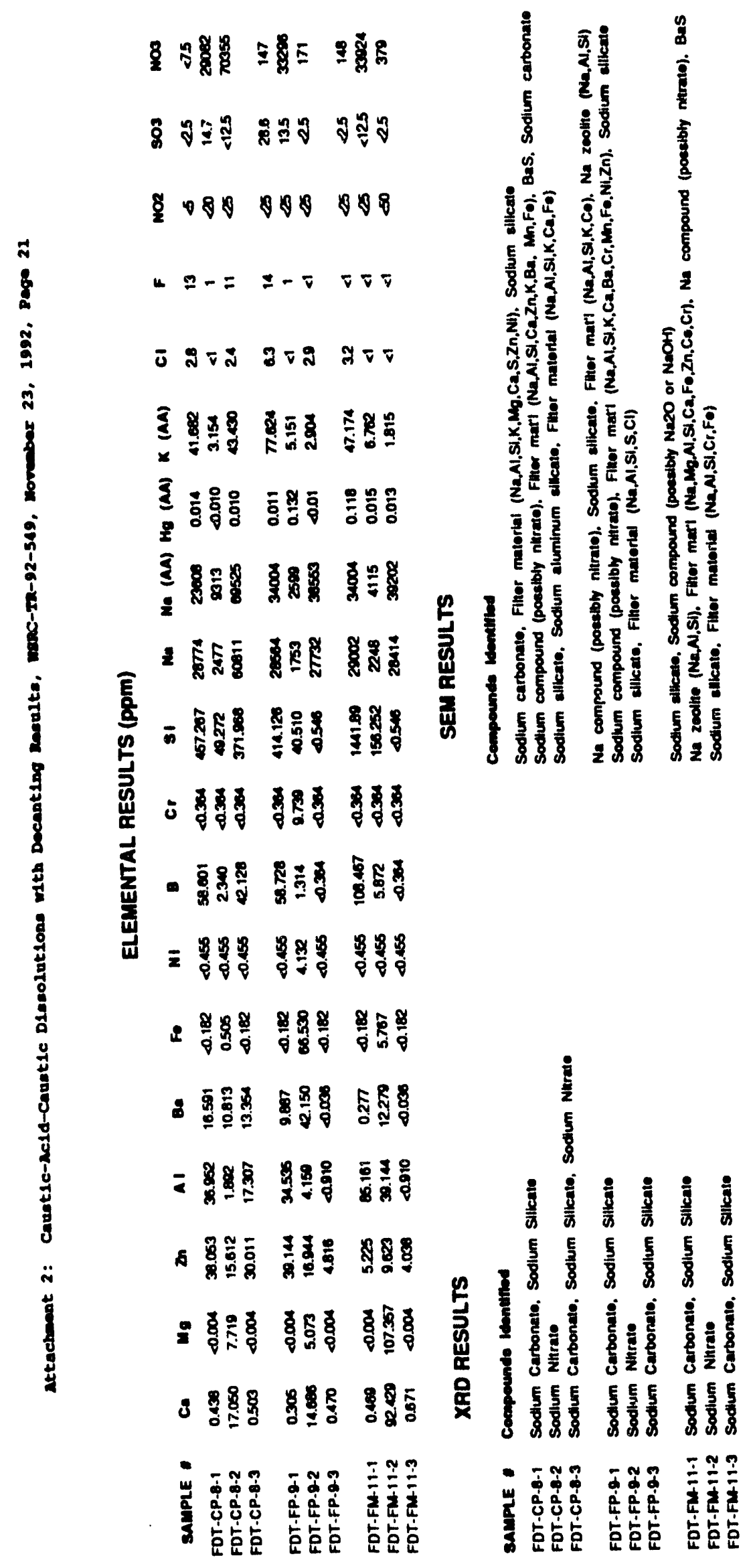




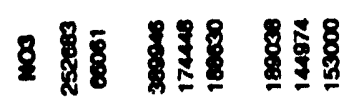

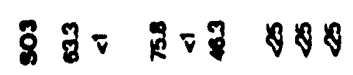

ชุำ

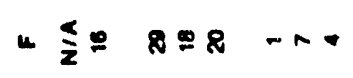

ธำ

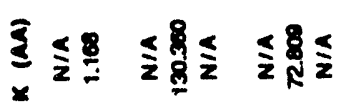

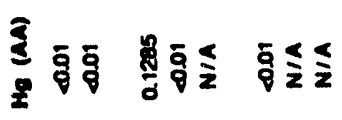

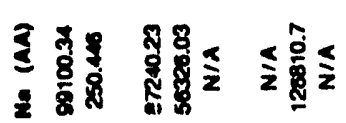

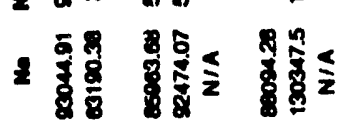

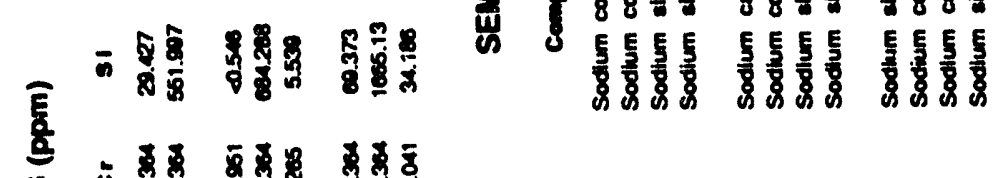

1

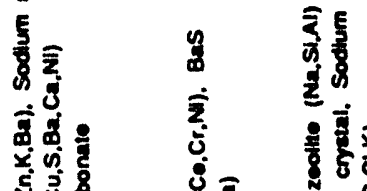

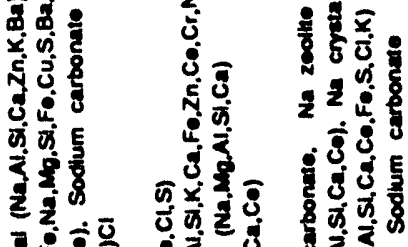

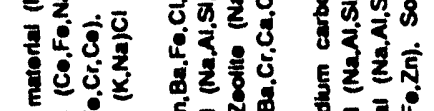

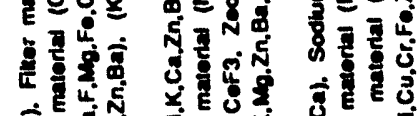

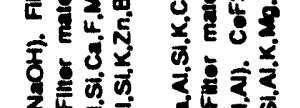

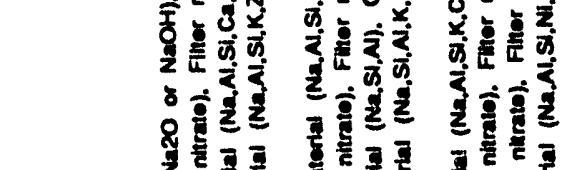

20

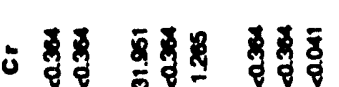

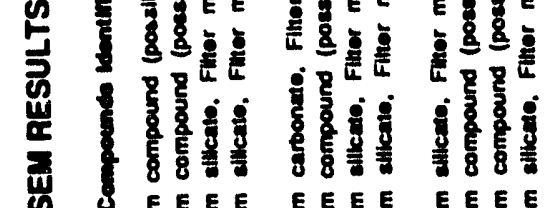

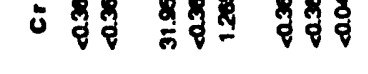

-

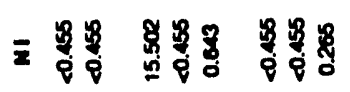

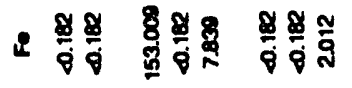

-

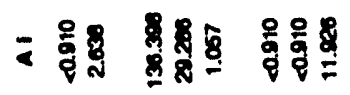

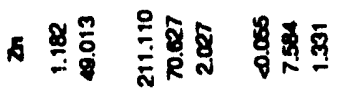

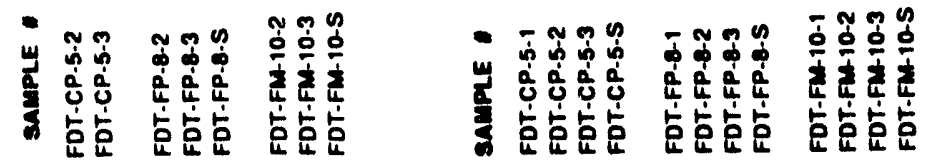




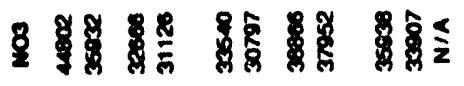

3ำ

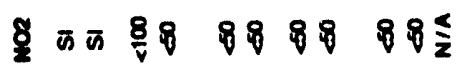

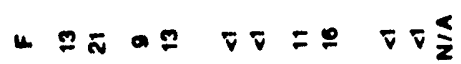

a

8

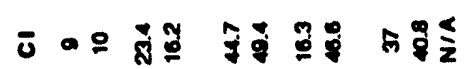

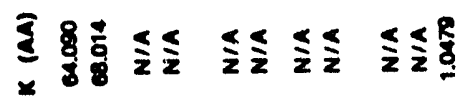

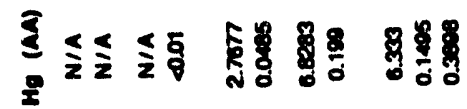

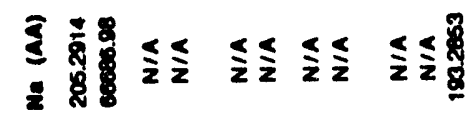

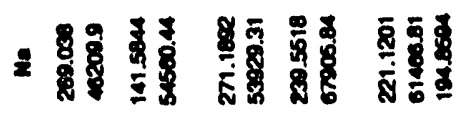

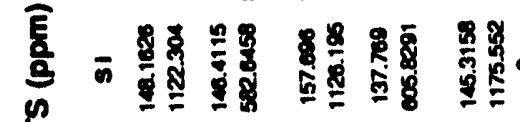

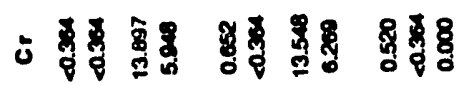

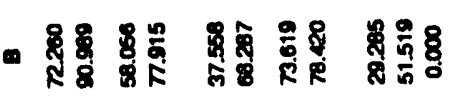

三

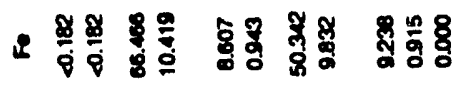

ว

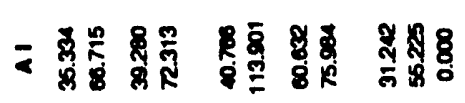

ร)

:

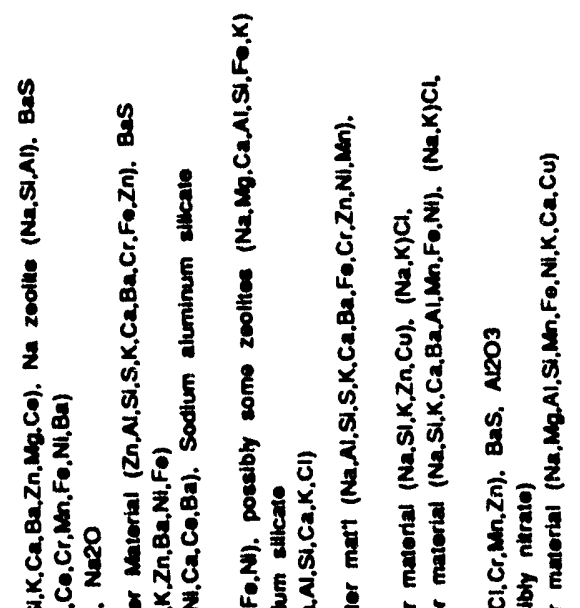

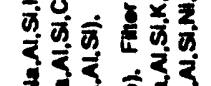

int

inin

sin

sing

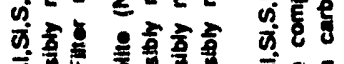

Ifit

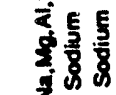

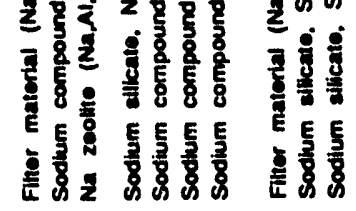

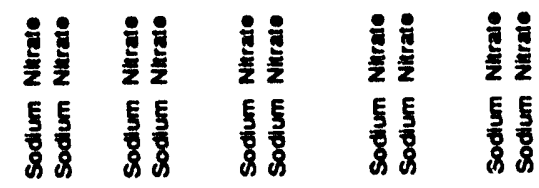

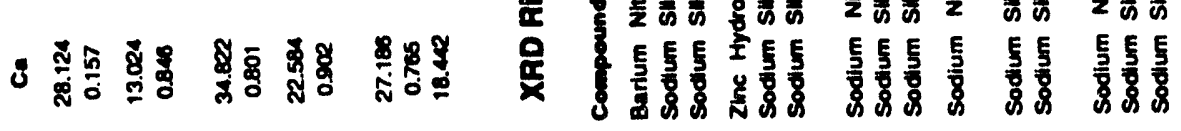

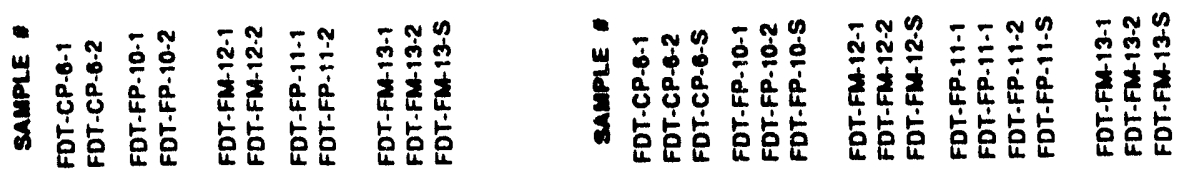




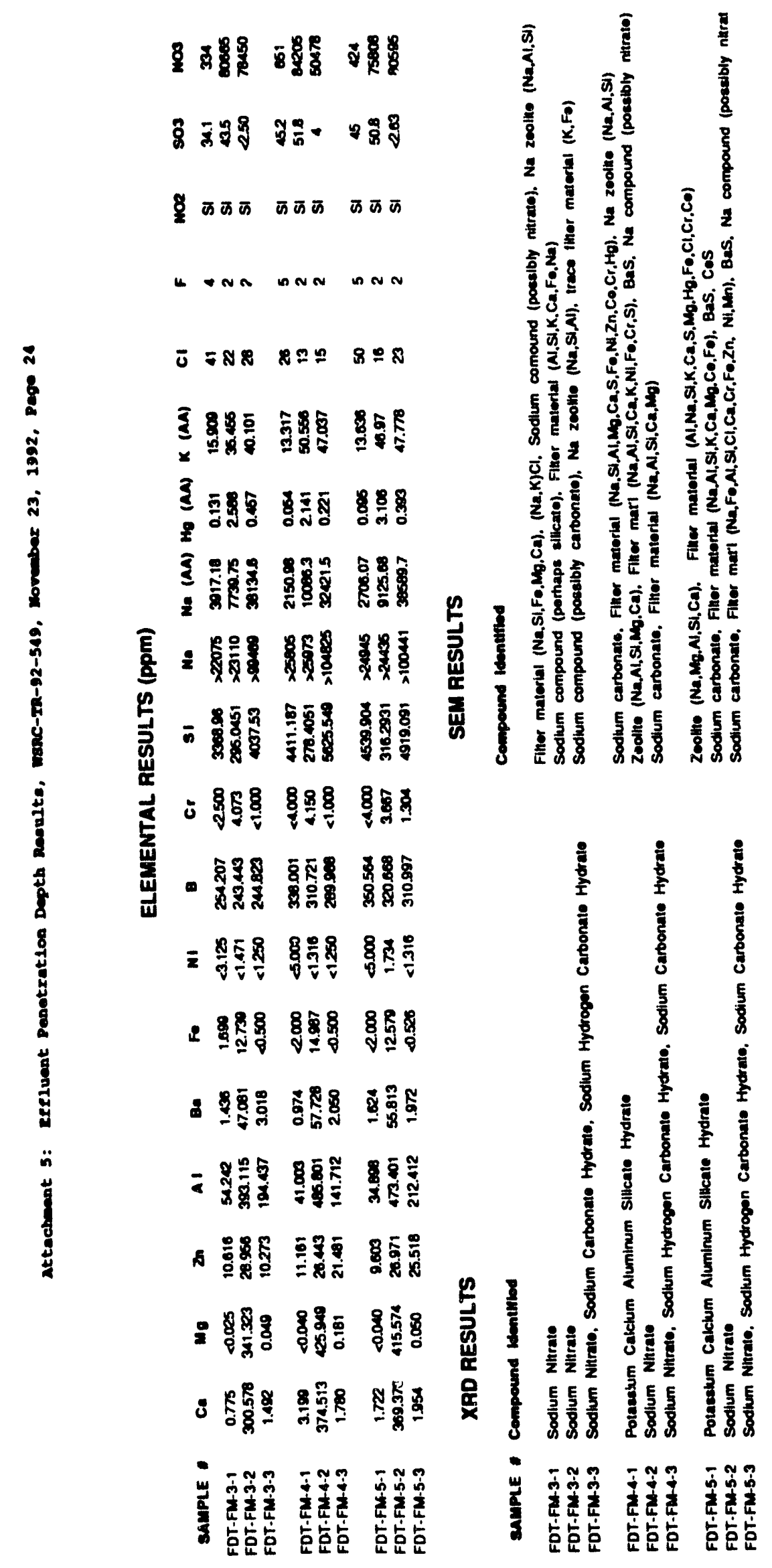




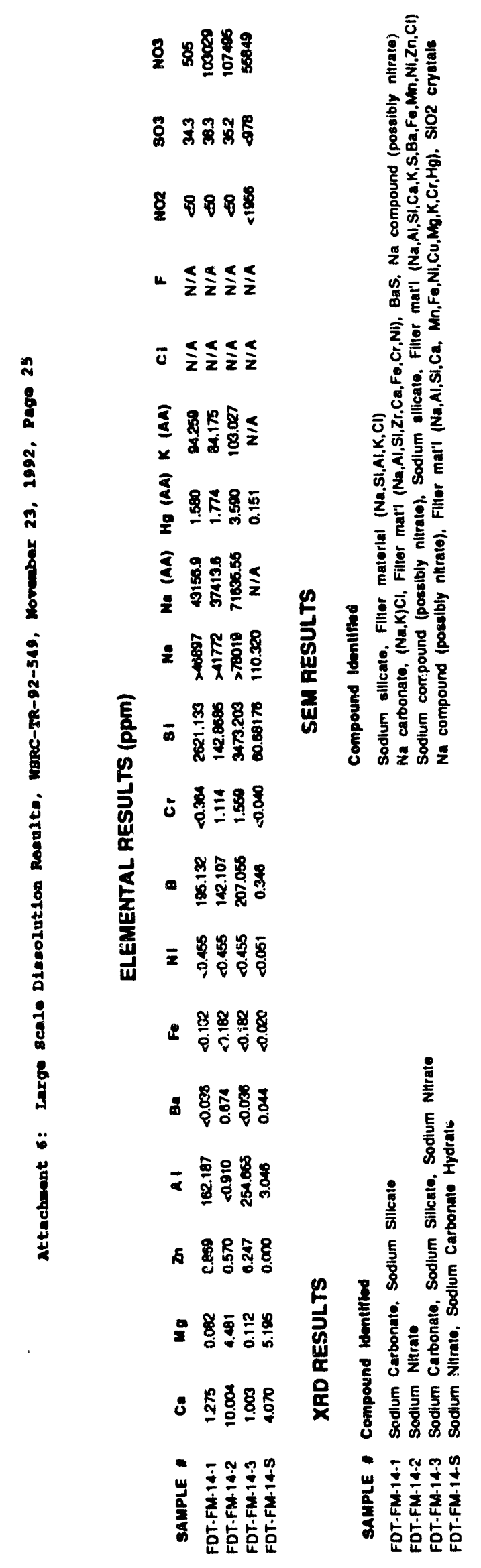




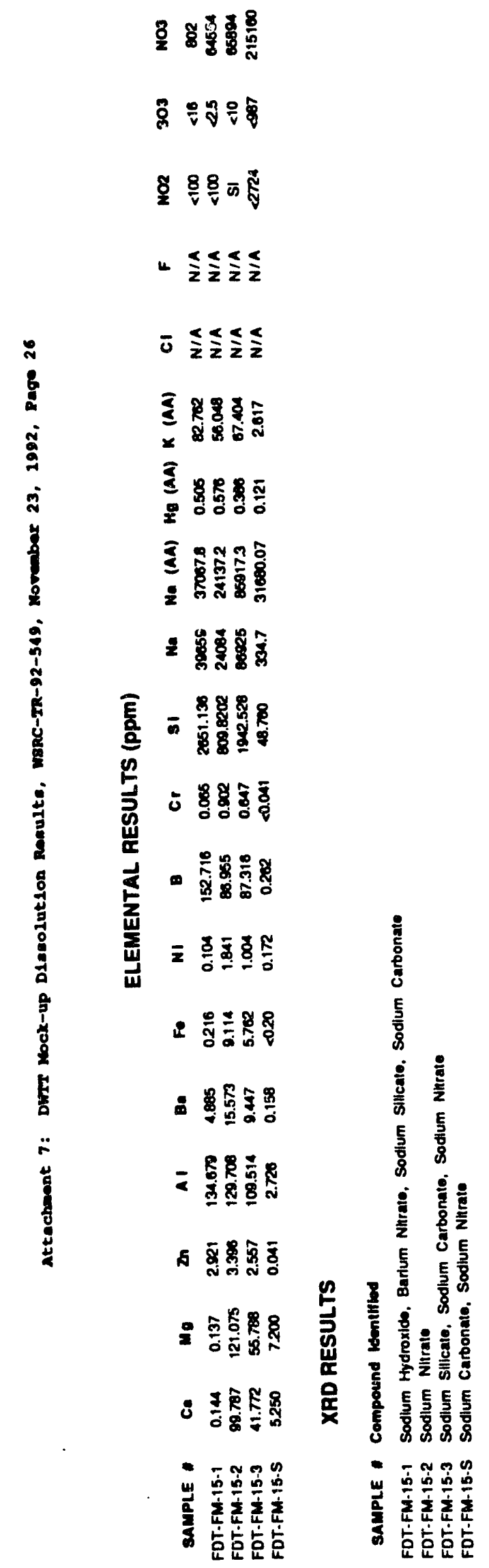



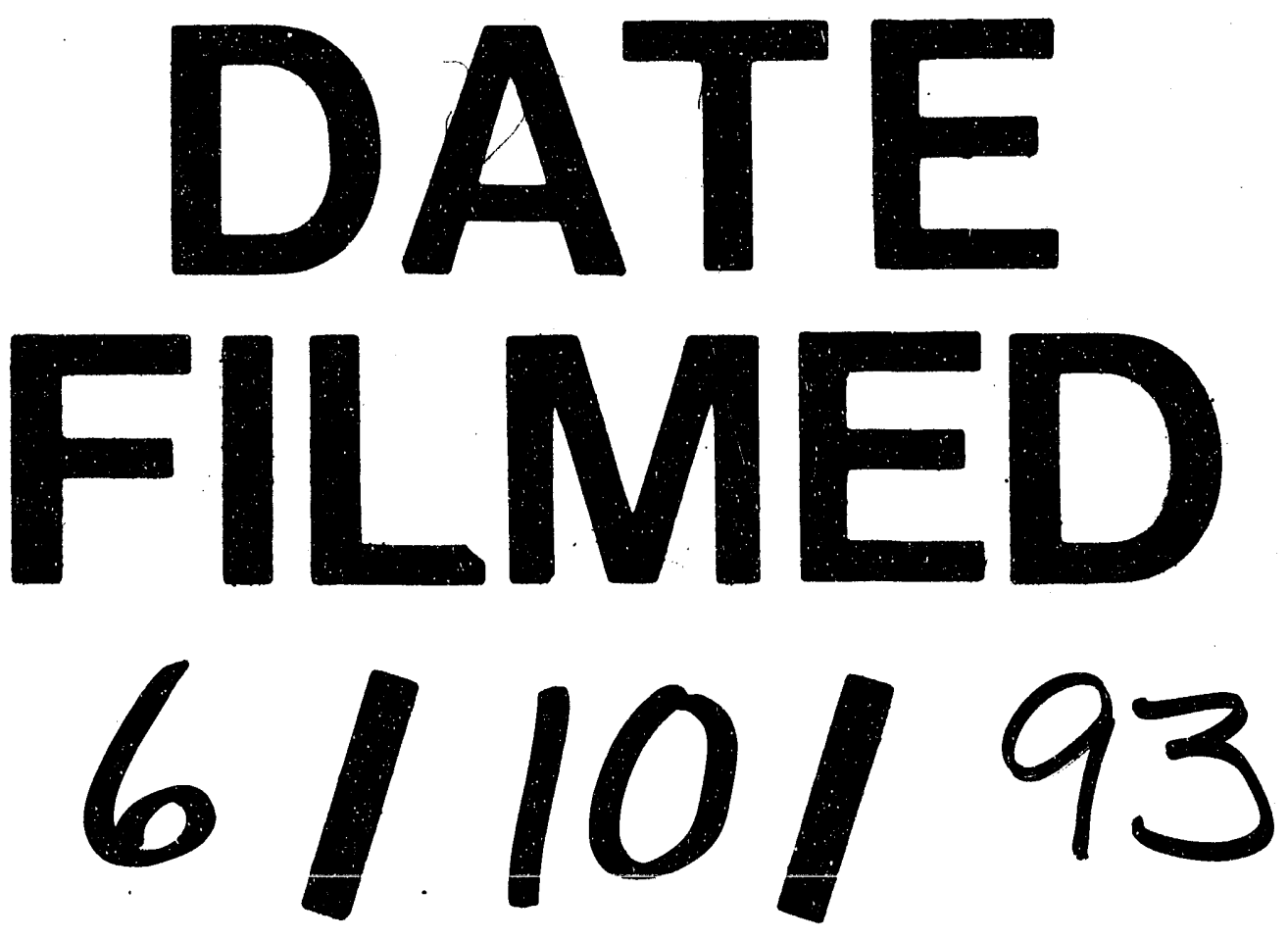
